\title{
IDENTIFIKASI KEKAR DESA PATTONTONGAN KECAMATAN MANDAI KABUPATEN MAROS, SULAWESI SELATAN
}

Agung Hasan, De Leonard Pasteur Simanjorang, Islamiah Nursalim, Mufly Fadla Syihab, Nur Lailiah Karepesina, Ervin Budi Sanjaya, Sadilah, Muh. Azhari Ramlan, Muh Resky Ariansyah, Muhammad Altin Massinai*, Muhammad Fawzy Ismullah Massinai

Departemen Geofisika, Universitas Hasanuddin, Makassar

* Penulis koresponden. Alamat e-mail: altin@science.unhas.ac.id

\begin{abstract}
Abstrak
Pelaksanaan kegiatan survey telah dilakukan di sekitar daerah pertambangan di Desa Patontongan, Kecamatan Mandai, Kabupaten Maros, Sulawesi Selatan. Pada penelitian ini, pengukuran dilakukan berulang kali dengan menggunakan alat yaitu kompas geologi. Hasil pengukuran di lapangan diperoleh beberapa nilai strike-dip pada lokasi struktur kekar yang berbeda, sehingga pada daerah tersebut mengiindikasikan terdapat kekar. Data strike-dip yang diperoleh kemudian diolah menggunakan software DIPS untuk menghasilkan Diagram Rosette. DIPS digunakan untuk melakukan analisis orientasi data geologi dan juga berhubungan dengan analisis teknik struktur batuan. Hasil Diagram Rosette memperlihatkan bahwa arah jurus kekar yang terdapat di Desa Patontongan ini mengarah hampir UtaraSelatan serta berarah Timur Laut-Barat Daya. Dengan melihat Diagram Rosette maka dapat disimpulkan gaya pembentuk struktur pada lokasi tersebut berarah Barat-Laut Tenggara.
\end{abstract}

Kata kunci: DIPS, Strike-dip, Diagram Rosette.

\begin{abstract}
The survey was carried out around the mining area in Patontongan Village, Mandai District, Maros Regency, South Sulawesi. In this study, measurements were made repeatedly using a geological compass. The results of measurements in the field obtained several strike-dip values at the location of different geological structures, so that in the area indicated there was fracture. The strike-dip data obtained is then processed using the DIPS software to produce a Rosette Diagram. DIPS is used to conduct orientation analysis of geological data and is also related to analysis of rock structure techniques. The results of the Rosette Diagram show that the direction of the strike found in Patontongan Village is almost North-South and has a Northeast-Southwest direction. By looking at the Rosette Diagram, it can be concluded that the structure forming the location in the Southeast-Northwest direction.
\end{abstract}

Keywords: DIPS, Strike-dip, Rosette Diagram 


\section{Pendahuluan}

Geologi struktur merupakan studi mengenai distribusi tiga dimensi baik tubuh batuan maupun permukaannya, dan komposisi internalnya. Geologi struktur juga melingkupi bentuk yang dibahas pada geomorfologi, metamorfisme dan geologi rekayasa. Dengan mempelajari struktur tiga dimensi batuan dan daerah, dapat dibuat kesimpulan mengenai tektonik, lingkungan pada masa lalu dan deformasinya.

Geologi struktur sangat diperlukan dalam berbagai bidang. Umumnya digunakan untuk eksplorasi dan mengetahui lapisan bumi serta proses terbentuknya struktur dalam suatu batuan, khususnya kekar, lipatan dan patahan. Selain itu, dengan memahamii geologi struktur, dapat diketahui proses terbentuknya jebakan sumber daya alam geologi seperti air, migas, dan mineral lainnya. Dengan mengenali jenis struktur yang tersingkap, maka dapat diketahui lebih jauh mengenai keadaan bentuk permukaan bumi dengan lebih baik.

Penelitian mengenai geologi struktur ini dimaksudkan untuk mengetahui bentuk dan struktur geologi khususnya struktur patahan dan lipatan di permukaan bumi secara nyata, proses terbentuk dan faktor yang mempengaruhinya sehingga tidak hanya memahami teori bagaimana proses terbentuknya patahan dan lipatan di permukaan bumi, adanya singkapan dan karakteristik suatu batuan, serta proses terjadinya di alam bebas. Tetapi dapat melihat langsung fenomena pembentukan patahan, lipatan, batuan, dan lain sebagainya secara nyata. Faktanya teori yang diperoleh sebelumya tidak sama dengan karakteristik bentuk permukaan bumi maupun karakteristik di alam secara nyata, sehingga perlu adanya pemahaman di lapangan mengenai faktor-faktor perbedaan yang terjadi di alam dengan teori yang selama ini dipahami (Pranata, 2016).

\section{Metode Penelitian}

Penelitian ini dilakukan di Desa Patontongan, Kecamatan Mandai, Kabupaten Maros, Sulawesi Selatan. Alat yang dibutuhkan untuk memperoleh data strike-dip adalah kompas geologi (Gambar 1). Pengukuran dilakukan berulang kali pada lokasi yang berbeda pada struktur kekar. Data strike-dip yang diperoleh kemudian diolah menggunakan software DIPS untuk menghasilkan Diagram Rosette.

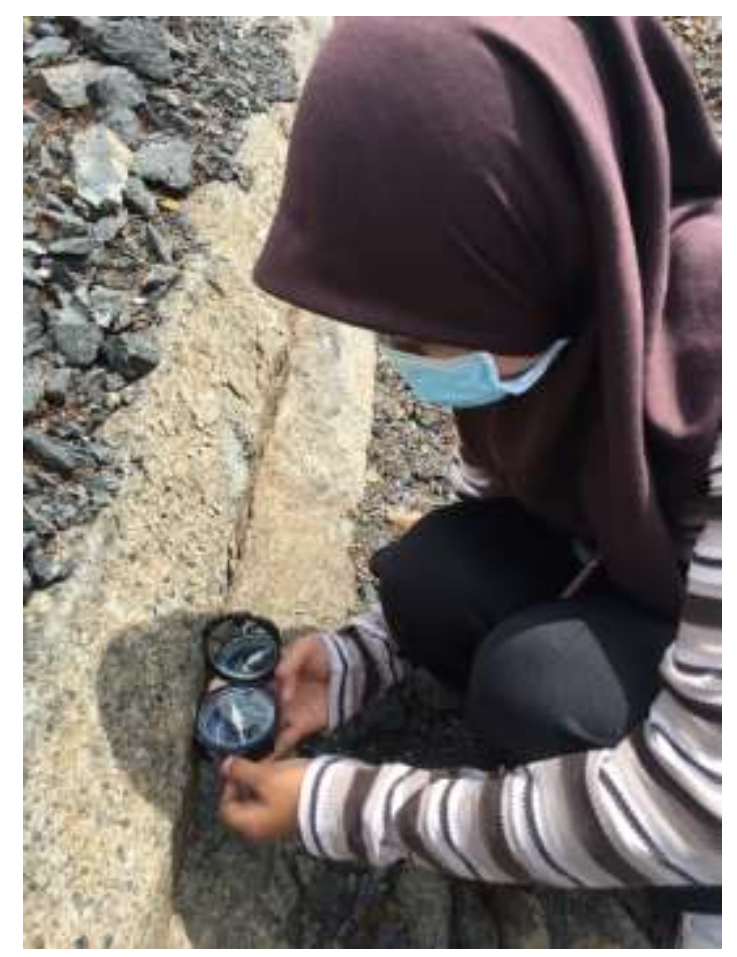

Gambar 1. Pengukuran strike-dip menggunakan kompas geologi di daerah penelitian.

\section{Hasil}

Berdasarkan pada daerah peta geologi daerah penelitian, yaitu di Desa Patontongan, Kecamatan Mandai, Kabupaten Maros, dapat dilihat bahwa yang mendominasi daerah 
tersebut adalah Formasi Camba dan Batuan Gunungapi Formasi Camba, dan juga terdapat endapan aluvium, danau dan pantai. Pada Formasi Camba dapat dilihat bahwa terdapat basal dan retas basal dalam jumlah singkapan yang tidak terlalu luas (Sompotan, 2012).

Berdasarkan sifat fisik, ukuran butir, genesa dan batuan penyusun di Kecamatan Mandai, maka jenis tanah yang dijumpai adalah alluvial muda dan litosol. Alluvial muda adalah endapan aluvium (seperti endapan di rawa, pantai dan sungai) dengan umur Kuarter (resen) dan berada pada daerah pedataran dengan ketinggian 0-60 m. Sedangkan litosol adalah tanah hasil pelapukan batuan induk, yaitu batuan intrusi (beku) dan/ atau batuan sedimen yang berada pada daerah perbukitan intrusi dengan tinggi $3-1.150 \mathrm{~m}$ dan sudut lereng $<70 \%$. Kenampakan seperti warna coklat kemerahan, ukuran butir beragam mulai lempung hingga pasir lempungan, agak kompak, dan tebal 0,2-4,5 m. Luas penyebarannya sekitar $37,60 \%\left(608,79 \mathrm{~km}^{2}\right)$ dari luas Kabupaten Maros, meliputi Kecamatan Mallawa, Camba, Bantimurung, Cenrana, Simbang, Tompobulu, Tanralili dan Mandai.

\section{Jenis Kekar}

Kekar (Joint) adalah retakan pada batuan yang belum mengalami pergeseran. Kekar dapat terbentuk baik secara primer (bersamaan dengan pembentukan batuan, misalnya kekar kolom (Gambar 2) dan kekar melembar pada batuan beku) maupun secara sekunder (setelah proses pembentukan batuan, umumnya merupakan kekar tektonik) (DeGraff, 1987).

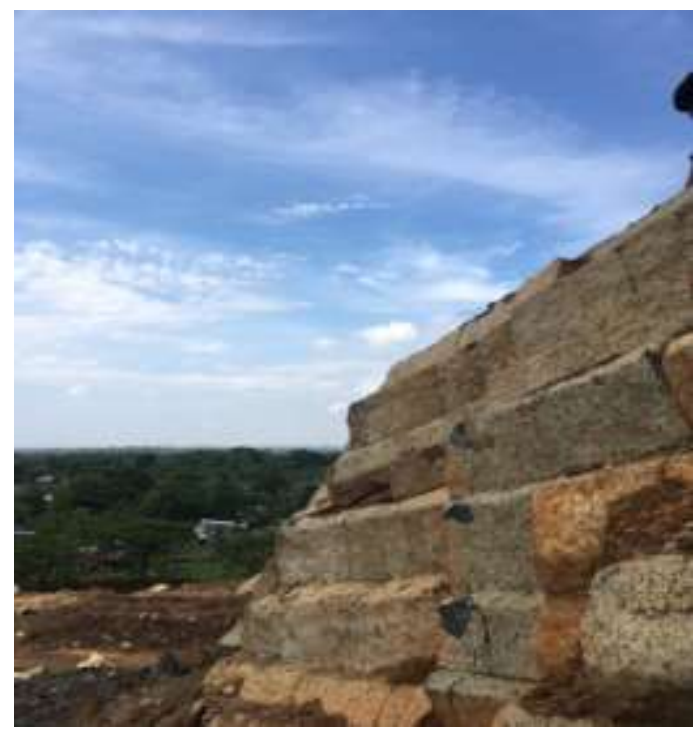

Gambar 2. Kekar Kolom (Columnar Joint)

Kekar adalah struktur yang terbentuk pada batuan dengan pergeseran yang sedikit atau tidak sama sekali. Kekar yang terdapat di Mandai, Sulawesi Selatan adalah kekar non systemic. Kekar non systemic pada lokasi penelitian adalah kekar yang susunannya tidak teratur.

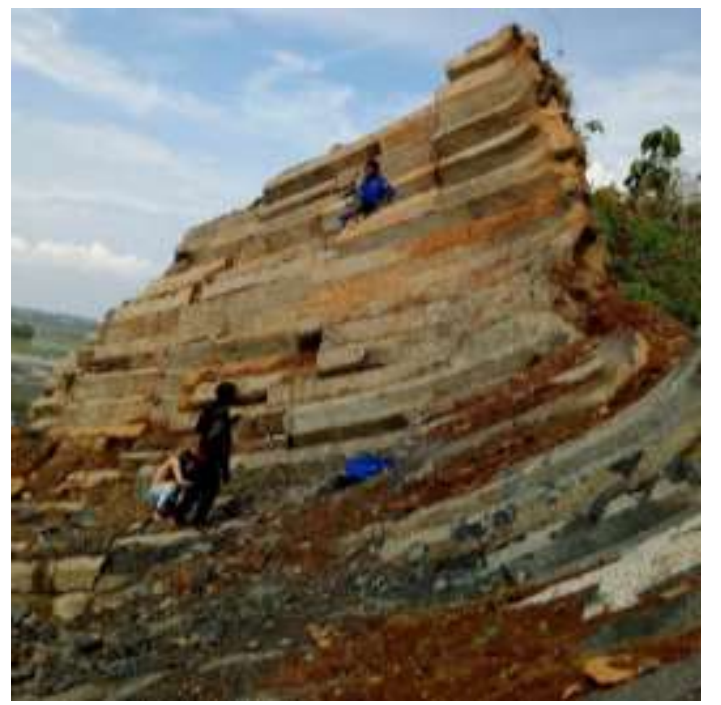

Gambar 3. Kekar Gerus (shear joint) 


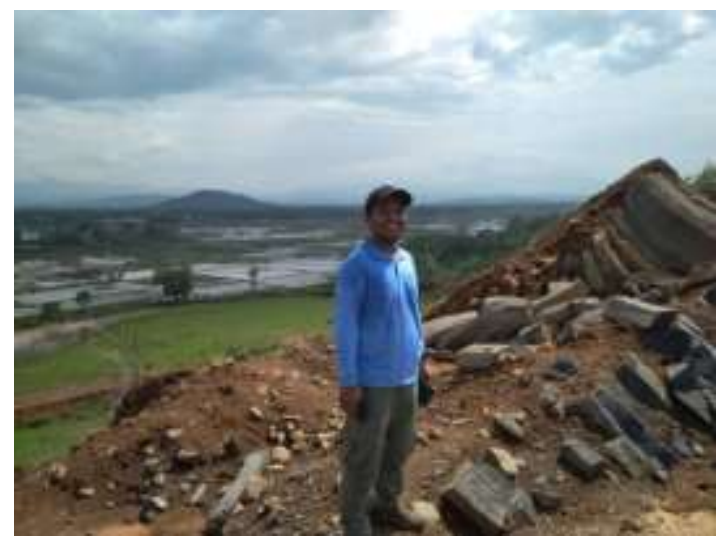

Gambar 4. Kekar Tensional (Tensional Joint)

Jenis kekar yang ditemukan di daerah penelitian adalah kekar gerus/ shear joint (Gambar 3) dan kekar tensional/ tensional joint (Gambar 4). Dikategorikan sebagai kekar gerus karena lapisan yang ada di daerah penelitian memiliki ciri rekahan yang membentuk pola saling berpotongan membentuk sudut lancip dengan arah gaya utama. Sedangkan kekar tensional di daerah penelitian memiliki ciri rekahan yang berpola sejajar dengan arah gaya utama.

\section{Hasil Olah Data Program DIPS}

DIPS adalah program yang dirancang untuk melakukan analisis orientasi data geologi. Programnya mampu untuk berbagai aplikasi dan dirancang dengan baik untuk mencapai pengguna proyeksi stereografi yang diinginkan untuk memanfaatkan alat yang lebih canggih dalam analisis data geologi. Selain itu, banyak fitur komputasi tersedia, seperti penyusunan orientasi secara statistik pengelompokan, rata-rata penghitungan orientasi dan kualitatif dan analisis atribut fitur kuantitatif. DIPS telah dirancang untuk analisis fitur terkait dengan analisis teknik struktur batuan. Namun, format bebas dari file data DIPS memungkinkan analisis data berbasis orientasi apa pun.

Pada penelitian ini, penggunaan software DIPS terbatas untuk penentuan arah penjurusan kekar pada daerah penelitian yaitu Desa Patontongan dengan menggunakan Diagram Rosette.

Plot roset konvensional dimulai dengan bidang horizontal (diwakili oleh lingkaran khatulistiwa (luar) dari plot). Histogram radial (dengan segmen busur dan bukan batang) dilingkarkan pada lingkaran ini, menunjukkan kepadatan bidang yang memotong permukaan horizontal ini. Batas orientasi radial (azimuth) dari segmen busur sesuai dengan rentang strike bidang atau sekelompok bidang yang diwakili oleh segmen tersebut. Dengan kata lain, Diagram Rosette adalah histogram radial dari kepadatan atau frekuensi dari strike.

Berdasarkan data hasil pengukuran di lapangan, diperoleh beberapa nilai strike-dip pada daerah yang terdapat kekar. Data ini yang kemudian dimasukkan ke dalam software DIPS untuk menghasilkan Diagram Rosette.

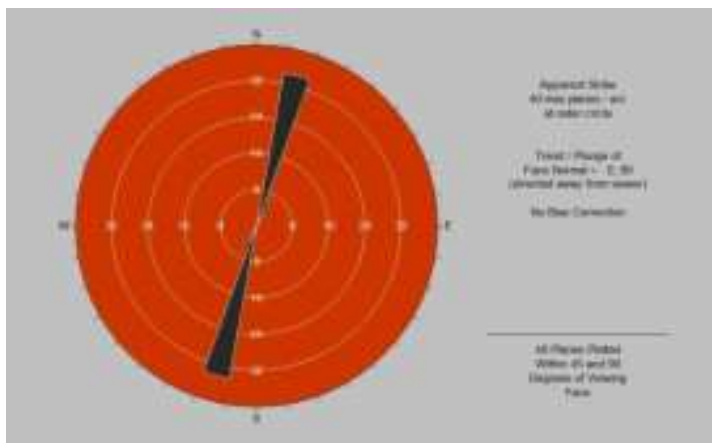

Gambar 5. Diagram Rosette

Hasil Diagram Rosette pada Gambar 5 memperlihatkan bahwa arah jurus kekar yang terdapat di Desa Patontongan ini mengarah hampir Utara-Selatan serta berarah Timur Laut-Barat Daya. Dengan melihat Diagram Rosette maka dapat disimpulkan gaya pembentuk struktur pada lokasi tersebut berarah Barat Laut-Tenggara. 


\section{Kesimpulan}

Berikut kesimpulan dari penelitian ini yaitu:

1. Secara umum struktur geologi yang ditemukan pada daerah penelitian adalah kekar dan sesar. Dimana jenis kekar yang menyusun struktur geologi pada daerah tersebut adalah kekar gerus (shear joint) dan kekar tensional (tensional joint).

2. Diagram Rosette dari data pengukuran strike-dip di lapangan merepresentasikan nilai suatu fenomena alam dalam sudut atau arah tertenu.

3. Arah jurus kekar yang terdapat di Desa Patontongan mengarah hampir UtaraSelatan serta berarah Timur Laut-Barat Daya.

\section{Saran}

Dalam penelitian selanjutnya, penulis menyarankan:

1. Perlu dilakukan analisis lebih jauh terhadap struktur geologi yang ada di daerah penelitian.

2. Menambah literatur atau referensi terkait penelitian yang dilakukan.

\section{Ucapan Terima Kasih}

Tim penulis mengucapkan terima kasih kepada Program Studi Geofisika Unhas dan masyarakat Desa Patontongan, Kecamatan Mandai, Kabupaten Maros, Provinsi Sulawesi Selatan.

\section{Daftar Pustaka}

Pranata, Mohammad Bagus. 2016. Petrogenesis Batuan Beku dan Karakteristik Kekar Tiang di Bukit Pajangan, Desa Sidomulyo, Kecamatan Purworejo, Kabupaten Purworejo, Jawa Tengah.
Departemen Teknik Geologi Universitas Diponegoro. Vol.1 No.2, page: 41-49.

Sompotan, Armstrong. 2012. Struktur Geologi Sulawesi. Institut Teknologi Bandung. Bandung.

DeGraff, James. 1987. Surface morphology of columnar joints and its significance to mechanics and direction of joint growth. Department of Earth and Atmospheric Sciences. Vol.99 No.16, page: 605-617. 